\title{
FINNISH GRADUATED PHYSICS TEACHERS' VIEWS ABOUT THEIR TEACHER EDUCATION PROGRAM: THE DISPARITY BETWEEN THE NEEDS AND DELIVERY
}

\author{
Risto Leinonen ${ }^{1}(\mathbb{D})$, Markku Haaranen ${ }^{2}$ (D), Mikko Kesonen ${ }^{1}$ (D), Mika Koponen ${ }^{3}$ (D), \\ Pekka E. Hirvonen $^{1}$ iD, Mervi A. Asikainen ${ }^{1}$ iD \\ ${ }^{1}$ Department of Physics and Mathematics, University of Eastern (Finland) \\ ${ }^{2}$ North Karelia Municipal Education and Training Consortium, Riveria (Finland) \\ ${ }^{3}$ Department of Education, University of Helsinki (Finland) \\ risto.leinonen@ueffi,m.haarane@gmail.com,mikko.kesonen@ueffi,mika.koponen@helsinki.fi, \\ pek.ka.birvonen@kitee.fi,merviasikainen@ueffi
}

Received September 2019

Accepted November 2019

\section{Abstract}

In this article, graduated physics teachers' views about their teacher education program and professional needs are evaluated. With respect to teacher knowledge, Physical Knowledge for Teaching (PKT) framework consisting of six domains related to content knowledge and pedagogical content knowledge was developed based on the framework of Mathematical Knowledge for Teaching. PKT was utilized in the design of a Likert scale instrument that aims to discover teachers' views concerning these six domains from two separate viewpoints: to what extent the domains were covered in their teacher education program concerning the domains, and how important is that theme for their profession. Results revealed that teachers see that the domains related to common content knowledge and structures of physics have been addressed adequately in their teacher education but characteristics of other domains, such as teaching methods, evaluation, and motivating learners, received less favorable evaluations. With respect to the importance of different domains for teacher profession, teachers valued the importance of every domain of teacher knowledge highly. These findings suggest that the greatest deficiencies in this physics teacher education program lie on addressing pedagogical content knowledge with its various sub-domains. Our PKT framework offers a promising base for evaluating physics teacher knowledge. We suggest that a framework for teacher knowledge should be explicitly introduced for pre-service teachers in their education so that they could evaluate their knowledge and professional needs better.

Keywords: In-service teacher education, Teacher knowledge, Physics teachers.

\section{To cite this article:}

Leinonen, R., Haaranen, M., Kesonen, M., Koponen, M., Hirvonen, P.E., \& Asikainen, M.A. (2020). Finnish graduated physics teachers' views about their teacher education program: The disparity between the needs and delivery. Journal of Technology and Science Education, 10(1), 101-116. https://doi.org/10.3926/jotse.820 


\section{Introduction}

Internationally, Finland has a good reputation in science teacher education due to high results received in international comparisons, such as PISA and TIMMS (OECD, 2018; TIMMS \& PIRLS, 2015). However, recently the ranking of Finland in these comparisons has declined, even if Finland is still amongst the high-achieving countries. Besides this, findings indicate that the interest towards science and scientific careers of Finnish youth are amongst the lowest ones in OECD countries (OECD, 2015). These findings cause a concern for science teacher educators because qualified and motivated youth are a key factor in building a sustainable future for small countries such as Finland. Hence, it is important to critically evaluate teacher education programs in order to assure that forth-coming teachers will have the necessary know-how for their profession. In the course of this article, graduated Finnish physics teachers' views about their teacher education program are evaluated.

\subsection{Teacher Knowledge}

Whilst referring to the knowledge and skills that teachers need in their professions, the term teacher knowledge is often used. The afore-mentioned term and its characteristics are not defined unambiguously but it can be evaluated from various perspectives. However, there is a rather wide consensus within the scientific community that the general framework presented by Shulman (1986) defines the most essential elements of teacher knowledge to some extent. In this framework, the teacher knowledge is presented to consist of three domains, namely content knowledge, pedagogical content knowledge, and curricular knowledge. Later, Shulman supplemented this framework by presenting a fine-structure for it, with altogether seven domains labelled content knowledge, general pedagogical knowledge, curriculum knowledge, pedagogical content knowledge, knowledge of learners and their characteristics, knowledge of educational contexts, and knowledge of educational ends, purposes, and values (Shulman, 1987).

The afore-mentioned frameworks do not take any stand for any particular subject, but they describe teacher knowledge in general. However, there are also studies concerning subject-specific teacher knowledge and pedagogical content knowledge for different disciplines (e.g. Koponen, Asikainen, Viholainen \& Hirvonen, 2017; Keller, Neumann \& Fischer, 2017; van Driel, Verloop \& de Vos, 1998). Typically, these studies are constructed based on Shulman's framework or are otherwise well in agreement with it. These studies tie Shulman's framework to subject-specific content knowledge, and thus they can bring more pragmatic aid for teachers and teacher educators than Shulman's framework (Shulman 1986, 1987).

One widely used evidence-based framework built upon Shulman's ideas is labelled Mathematical Knowledge for Teaching (MKT) (Ball, Thames \& Phelps, 2008). As the name indicates, the MKT refers to teaching mathematics, and the domains of the framework and their descriptions are subordinate for the subject. The underlying idea of the framework is that the two ends are subject matter knowledge and pedagogical content knowledge, and they both have their own sub-structures with three domains each as seen in Figure 1.

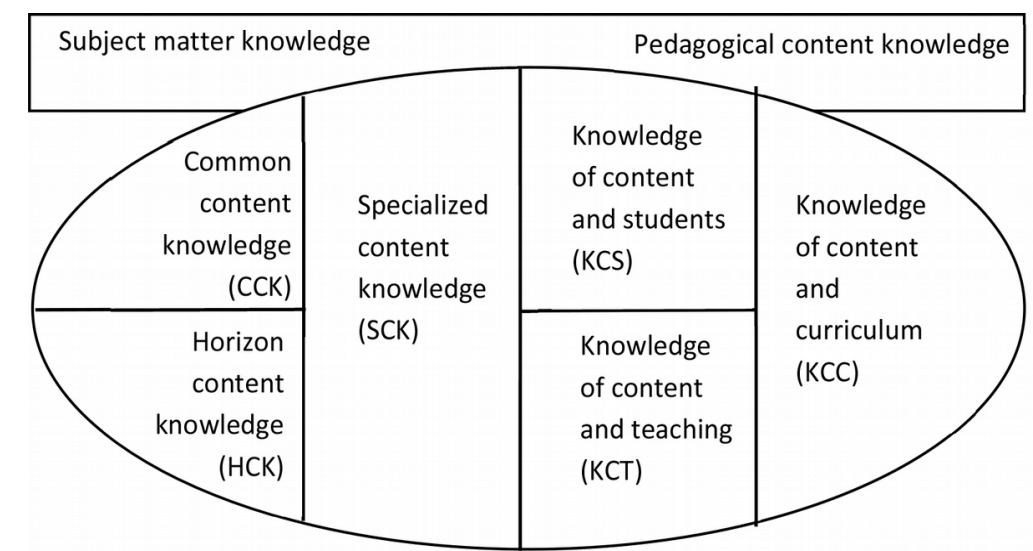

Figure 1. The domains of Mathematical Knowledge for Teaching (MKT) framework (Ball et al., 2008) 
Subject matter knowledge consists of three knowledge types. Common content knowledge (CCK) means knowledge that the people knowing and using mathematics possess. Specialized content knowledge (SSK), in turn, stands for knowledge essential for effective teaching of mathematics. Horizon content knowledge (HCK) describes how mathematics topics are related to each other in the body of topics of mathematics in the curriculum. Pedagogical content knowledge also includes three knowledge domains. Knowledge of content and students (KCS), means knowledge of how students learn particular content, whereas Knowledge of content and teaching (KCT) denotes knowledge about effective strategies for certain teaching events and topics. Knowledge of content and curriculum (KCC) contains knowledge of curricula, for instance, how and when certain mathematics topic is typically taught. (Ball, 2008)

\subsection{Physical Knowledge for Teaching (PKT) Framework}

With respect to previous frameworks suggested for teacher knowledge in physics, knowledge base of physics teacher education has been previously introduced by Asikainen and Hirvonen (2010). In this framework, teacher knowledge is divided into two sections: knowledge of physics and knowledge of teaching physics. Knowledge of physics consists of conceptual understanding, structures of physics, history of physics, philosophy of physics, and experimental work (knowledge of physics). Knowledge of teaching physics stands for instructional approaches (skills and instructional implementations), mathematical problem-solving, and students' preconceptions and models.

We think that one possible framework for characterizing teacher knowledge of physics could also be built upon MKT. There are several good reasons for this, and the major one emerges from the fact that both mathematics and physics have common features, such as hierarchical structure, logical thinking, utilizing models and equations, problem-solving. Naturally, these subjects are connected from the historical point of view (Dirac, 1940). Thus, we think that MKT offers a good starting point for evaluating physics teachers' knowledge when the framework is updated by adding certain distinctive features of physics and by removing exclusive mathematics features, as described below. As the domains seen in Figure 1 yet do not take a stand on the subject per se, the labels of the domains remain identical in the Physical Knowledge for Teaching (PKT) framework.

Regarding the domain descriptions below, various sources have been utilized in formulating them. General descriptions are mostly based on studies related to MKT model (Koponen, Asikainen, Viholainen \& Hirvonen, 2016; Ball et al., 2008; Hill, Ball \& Schilling 2008), whilst the parts related strictly to physics and teaching it originate from other sources (e.g. Asikainen \& Hirvonen, 2010; Halloun, 2004). This new framework is much more detailed than earlier ones and also offers possibilities for measuring teacher knowledge.

\subsubsection{Domains in Subject Matter Knowledge}

In one sense, common content knowledge (CCK) is the most evident domain of teacher's knowledge. In the context of physics teaching, it refers to pure physics content, such as theories, laws, concepts, notations, terminology, and methods of physics. This knowledge is utilized in other contexts than in teaching as well, e.g. in physics research and engineering.

Horizon content knowledge (HCK) refers to the hierarchical structure of physics and the essential elements within it. For example, the relationships between theories, models, phenomena, and observations are included in this domain. Besides, HCK includes general information concerning knowledge construction process and dualistic nature - namely, the interaction between phenomena and theory - of physics.

Specialized content knowledge (SCK) includes elements related to teaching but that are still strongly connected to content knowledge rather than for pedagogical content knowledge. The domain includes knowledge about choosing appropriate exercises and illustrative examples and knowledge about proper assignments for students with a certain level of knowledge for various topics. This domain also includes 
certain specific teaching tasks, such as grading exams that do not necessarily require pedagogical content knowledge. For example, recognizing an erroneous use of physics concepts belongs to this domain.

\subsubsection{Domains in Pedagogical Content Knowledge}

Knowledge of content and students (KCS) is a combination of knowing about students and knowing about physics. This includes, for example, teacher's familiarity with common alternative conceptions and other learning difficulties related to the subject. Besides, information about motivating examples and choosing appropriate tasks and understanding learners' use of language, possibly unorthodox from the viewpoint of physics, are included in this domain. According to Hill et al. (2008), KCS is the primary element in Shulman's PCK, as PCK addresses understanding of what makes learning certain topics difficult. For instance, recognizing a common alternative conception from student's answer relates to this domain.

Knowledge of content and teaching (KCT) combines knowledge concerning physics content and teaching. This includes but is not limited to choosing effective strategies for topics to be taught, organizing classrooms and experimental working, and promoting interaction and communication. For example, reacting to pupils' question in a way that helps them to discover their own answers requires subjectspecific knowledge from this domain. Also, different roles of a teacher belong to this domain.

The last domain Knowledge of content and curriculum (KCC) is the knowledge related to regulations coming from national and local curricula that set the guidelines and aims for teaching, i.e. topics to be taught and characterizations of other possible aims. Besides, knowledge about teaching materials, instruments, technology, etc. belong to this domain.

\subsection{Teachers' Views about Teacher Knowledge and their Education}

In the course of this section, teachers' views about their education and physics teacher knowledge with its domains and characteristics are introduced.

Asikainen and Hirvonen (2010) made a case study about the views of experienced physics teachers $(N=6)$ concerning physics teacher knowledge in Finland. Whilst reflecting the main findings from this study to PKT model, the importance of common content knowledge, such as including experimental work and some elements of specialized content knowledge, e.g. everyday life examples and helpful explanations were emphasized. Besides this, some elements of Knowledge of Content and Teaching were mentioned regularly, such as activating teaching strategies.

When the afore-mentioned teachers were prompted with the aid of Likert scale claims concerning teacher knowledge, certain new elements were highlighted. Conceptual understanding, the structure of physics, experimental work, and instructional approaches were considered important by all teachers, and students' preconceptions and models by many of them. Then again, physics history was seen as a neutral component for teacher knowledge by all teachers whilst the knowledge related to philosophy of physics and mathematical problem-solving divided participants' views. (Asikainen and Hirvonen, 2010).

Buabeng, Conner and Winter (2016) studied physics teachers' views about their preparedness to teach various physics topics and about the teacher education they had received in New Zealand. First, it was revealed that mostly teachers considered themselves well prepared to teach certain physics areas (e.g. mechanics and electricity) whilst some others (e.g. modern physics) received less favorable perceptions. This signals that there are differences within the domain of common content knowledge amongst these teachers.

Teachers' views about their teacher education showed that they evaluated their education to have prepared them well in terms of knowledge of learners and their development, monitoring and diagnosing learners with accurate helpful feedback concerning their learning, the curriculum goals, and teaching diverse students (Buabeng et al., 2016). With respect to more critical views concerning the education received, it 
was revealed that teachers did not seem to have gained adequate common content knowledge, understanding and implementing both national and local curricula, and utilizing ICT in their teaching (Buabeng et al., 2016).

Abd-El-Khalick and BouJaoude (1997) studied science (biology, chemistry, physics, medical lab technology, agriculture, or pharmacy) teachers' knowledge base in Beirut. It was shown that teachers have naïve ideas about nature of science and structures of their disciplines, and these ideas mostly did not differ according to their level of education, school level, or teaching experience. Teachers' concept maps showed them to have relatively inaccurate knowledge base in comparison to expert maps. Besides these, teachers had problems in connecting their disciplines to everyday life experiences and recognizing misconceptions. These findings suggest in their teacher education there are problems in the domains of common content knowledge, horizon content knowledge, and knowledge of content and students.

Koponen et al. $(2016,2017)$ have used MKT model for evaluating graduated mathematics teachers' views (often physics minors) about the teacher education they have received. It was revealed that especially the domains of Common content knowledge, Special content knowledge, Knowledge of content and students, and Knowledge of content and teaching would deserve more emphasis in teacher education according to graduated teachers which suggests that these domains have also a great importance for teachers' profession, even if this was not probed explicitly. Most of these mathematics teachers also teach physics which suggests these findings to be transferable to that context to some extent.

\subsection{Research Focus and Questions}

As the aim of teacher education is to provide teachers with the best possible skills and knowledge for their profession, we teacher educators should assure that our teacher education programs can deliver this. Therefore, it is important to evaluate existing teacher education programs to gain insights for possible improvements. This is in the focus of this article, and the research questions are formulated as follows:

1. How do graduated physics teachers evaluate their teacher education program in terms of different domains of teacher knowledge?

2. How do graduated physics teachers evaluate the importance of different domains of teacher knowledge for their profession?

\section{Context and Methods}

In this section, the context of the study and data gathering and analyzing methods are described.

\subsection{Physics Teachers' Education in Finland}

Physics teacher studies in Finland are given in universities by subject departments, departments of education, and teacher training schools. The main responsibility in studies lies on the subject department where both researchers and teachers are educated; students must take 90 ECTS credits minimum in their major. The remaining ECTS credits included in master's degree consist of general studies (e.g. English, communication skills), pedagogical studies (60 ECTS credits, including teaching practice), and minor studies for other subjects (60 ECTS credits, typically mathematics and/or chemistry for forth-coming physics teachers). The following descriptions introduce the education program as it has been for the teacher sample of this study.

Basic studies in physics (25 ECTS credits) consist of four lecture courses supplemented with weekly homework sessions and one laboratory course. Besides physics majors, these courses include students studying mathematics, chemistry, and computer science. The textbook used in the lecture courses is Physics for Scientists and Engineers by Knight (2014), and the topics covered include mechanics, thermal physics, oscillations and waves, electricity and magnetism, and modern physics. The courses are taught by experienced lecturers. The laboratory course in the entity addresses the themes taught in the lecture courses, and the underlying idea is that students make guided experiments and write succinct reports about these. 
Intermediate studies in physics (35 ECTS credits) include lecture courses addressing different topics of physics and a conventional laboratory course taken by both forth-coming researchers and teachers, both physics majors and minors. Besides, there are two special laboratory courses designed solely for physics teacher majors and minors. The lecture courses with homework sessions deepen the content addressed in basic studies, and each course has its own textbook (e.g. Hecht, 2002; Schroeder, 2000). The conventional laboratory includes guided experiments, and the course aims to develop learner's experimental skills and their abilities to write scientific reports. The first special laboratory course for teachers introduces the basics of experimental working and introduces conventional school laboratory experiments designed for lower secondary level. The latter course has a strong base in research, and it concentrates on theoretical foundations of experimental working, such as introducing aims of experimental working and different levels of openness. The actual course is implemented so that teacher students must design, implement, and report experimental laboratory work for a given topic for upper secondary level based on a theoretical framework presented for them (Nivalainen, Asikainen \& Hirvonen, 2013).

Advanced studies in physics (60 ECTS credits) is a research-based entity constructed based on the needs of physics teachers. Courses address themes that are shown to be important in teacher's profession, such as history of physics, physics as a structural science (e.g. Halloun, 2004; Kurki-Suonio \& Kurki-Suonio, 1994), conceptual physics, and problems in understanding physics (e.g. Hestenes, Wells \& Swackhamer, 1992; McDermott, 1990). Besides these, students must take two courses shared with forth-coming researchers, e.g. color science or material physics. Teacher students also make their bachelor and master theses related to teacher's profession. These can include research projects about learning certain physics topics at school, planning and conducting pedagogically designed experimental work, or teaching interventions, just to name but a few.

The entity of pedagogical studies (60 ECTS credits) is organized by the education department and the teacher training school. The preceding one provides general education related to learning and teaching, and the courses cover learning theories, methodological studies, small-scale research projects, studies about the regulations directing school-work, and ethical issues. Besides this, there are certain courses related to subject-specific pedagogy where some subject-specific teachings methods are addressed. The role of the teacher training school is to enable teacher students to practice teaching in authentic contexts under a supervision of specially educated teachers.

\subsection{The Participants}

The internet-survey was delivered for all teachers with physics as their major graduated from The Department of Physics and Mathematics between the years 2008 and 2016. The reason to limit the survey for the teachers graduated during this time period is that before this the teacher education program differentiated greatly from the one described above, and thus the sample would not be heterogeneous enough.

The total number of teachers was 45 , and 26 of them responded to the survey the answer percentage being 58\%. With respect to respondents' working experience, 58\% had worked less than five years whilst $42 \%$ had more than five years of teaching experience. 24 out 26 respondents had taken the entity of special courses for physics teachers during their education whilst the remaining two have had different courses, likely pure physics, during their education. These responses are not differentiated in the analysis.

\subsection{Data Gathering and Analysis}

The data gathering instrument was designed based on the PKT framework by three researchers with previous experience with the MKT model and related theories on teacher knowledge. The underlying idea for the instrument was to construct Likert scale claims related to the different domains of teacher knowledge, and to ask teachers to evaluate those from two viewpoints: how well were they educated in their teacher education program concerning that theme, and how important is that theme for teacher's work in their opinion. The claims were based on researchers' expertise in physics, physics education, and 
physics education research and various sources were utilized whilst formulating them (e.g. Finnish National Board of Education - FNBE, 2014; Kurki-Suonio \& Kurki-Suonio, 1994; Knight, 2014). During the construction of the survey, the claims and their formulations and wordings were evaluated and commented several times by the researchers before the actual data gathering.

The claims were formulated to be as pragmatic as possible so the teachers would not necessarily need theory-based information about teacher knowledge. Besides, the claims in the instrument were not grouped under the domain titles of PKT but rather according to practices of teaching so that teachers have better preparedness to answer them appropriately.

With respect to the PKT model, each claim was categorized belonging to one domain only for the sake of brevity of results, even if certain claims might have characteristics from more than one domain. The numbers of claims for each domain are seen in Table 1. The categorization was evaluated by two researchers who did not participate in constructing the survey, and during this process some changes for the categorization were implemented. The instrument is found in the following internet address: https://luma.uef.fi/physics-teacher-education-program-survey/ in both pdf and docx forms. The original instrument was in Finnish, and the translation to English was conducted by the authors.

\begin{tabular}{|l|c|c|}
\hline \multicolumn{1}{|c|}{ Domain } & $\begin{array}{c}\text { The number } \\
\text { of claims }\end{array}$ & The claims \\
\hline Common content knowledge (CCK) & 14 & \#1-\#8, \#14-\#19 \\
\hline Specialized content knowledge (SCK) & 14 & \#9_\#13, \#28, \#29, \#48-\#51, \#67-\#69 \\
\hline Horizon Content Knowledge (HCK) & 5 & $\#$ \#-\#24 \\
\hline Knowledge of Content and Teaching (KCT) & 10 & $\#$ \#25-\#27, \#30-\#35, \#56 \\
\hline Knowledge of Content and Students (KCS) & 15 & $\# 36-47, \# 53-\# 55$ \\
\hline Knowledge of Content and Curriculum (KCC) & 11 & $\# 52, \# 57-\# 66$ \\
\hline
\end{tabular}

Table 1. The number of claims for each domain of the modified MKT model and the ordinal numbers of claims

The data consists of teachers' answers for Likert scale claims. As there were 69 claims total, and each was to be evaluated from two viewpoints, teachers were expected to make 138 choices in the survey. The first viewpoint, physics teacher education received in terms of different domains of teacher's knowledge, was evaluated with a five-point Likert scale with the following wording:

$$
\begin{aligned}
& \text { How good know-how teacher education gave you for the following areas? } 1=\text { not at all, } 2=\text { poor, } \\
& 3=\text { mediocre, } 4=\text { good, } 5=\text { excellent. }
\end{aligned}
$$

It should be noted that of "I cannot say" was excluded from the options offered because with this wording teachers had to take a stand on each claim, and thus more representative data was expected to be received. Besides this, teachers could leave a blank answer.

The latter viewpoint, namely teachers' evaluations for the importance of different domains of teacher's knowledge for their profession, was evaluated with Likert scale claims with the following wording:

What is the significance of this area for teaching profession in your opinion? 1 = not significant at all, 2 = somewhat significant, $3=$ significant, $4=$ very significant, $5=$ I cannot say.

The use of Likert scale differs in this viewpoint as the option of "I cannot say" was also offered for the respondents. This was done since certain claims might be related to issues that might not have emerged yet in teachers' profession, even if it might prove to have great importance later, for example when national curricula are renewed. Besides, the wordings of the options differed between the questions for the sake of different nature of the questions.

In order to get an overview concerning teachers' views concerning addressing the six domains of teacher knowledge in their education and the importance of them for their profession, we wanted to get 
descriptive numbers. Thus, for both viewpoints the answer options were scaled so that the most negative option (not at all or not significant at all) corresponded to $0 \%$ and the most positive one (excellent or very significant) to $100 \%$. This way we could present results related to both viewpoints with the same scale, whilst 100\% refers to full satisfaction for the education received and importance for teacher's profession. Responses with the choice "I cannot say" in the latter viewpoint were excluded from the analysis for the sake of brevity.

After this, mean values for teachers' responses for all claims were calculated with the scale introduced above. Then these claim-specific mean values were used to calculate mean values and standard deviation for teachers' responses to six domains of teacher knowledge. Both "I cannot say" and blank answers were excluded from the analysis; the number of these was 0,5 out of 26 per claim in average. However, these figures offer a base for further discussion and interpretation of the results obtained so this choice is justified in this study.

Next, Wilcoxon Signed Rank test was used to find out the statistically significant differences between teachers' received know-how and experienced importance. The Wilcoxon Signed Rank Test (Roster, Glynn \& Lee, 2006) is a frequently used nonparametric test for paired data.

\section{Results}

Figure 2 shows a summary about teachers' evaluations for the six domains of teacher knowledge concerning their know-how received in their education and the importance of them for their profession. This gives an overview about the domains teachers were or were not satisfied in their education and that which ones they valued for their profession.

Three important observations can be made from Figure 2. First, there seem to be clear differences between the two viewpoints evaluated, especially in the domains of SCK, KCT, and KCC. Second, teachers seem to be quite satisfied for their education related to the domains of CCK and HCK (75\%-76\%) but only moderately to the domains of SCK, KCT, KCS, and KCC (40\%-51\%). Third, teachers value all the domains of teacher knowledge for their profession rather highly, with the range from $72 \%$ to $90 \%$. These findings signal that teachers evaluate that there is a great disparity between the content taught for them and their actual needs.

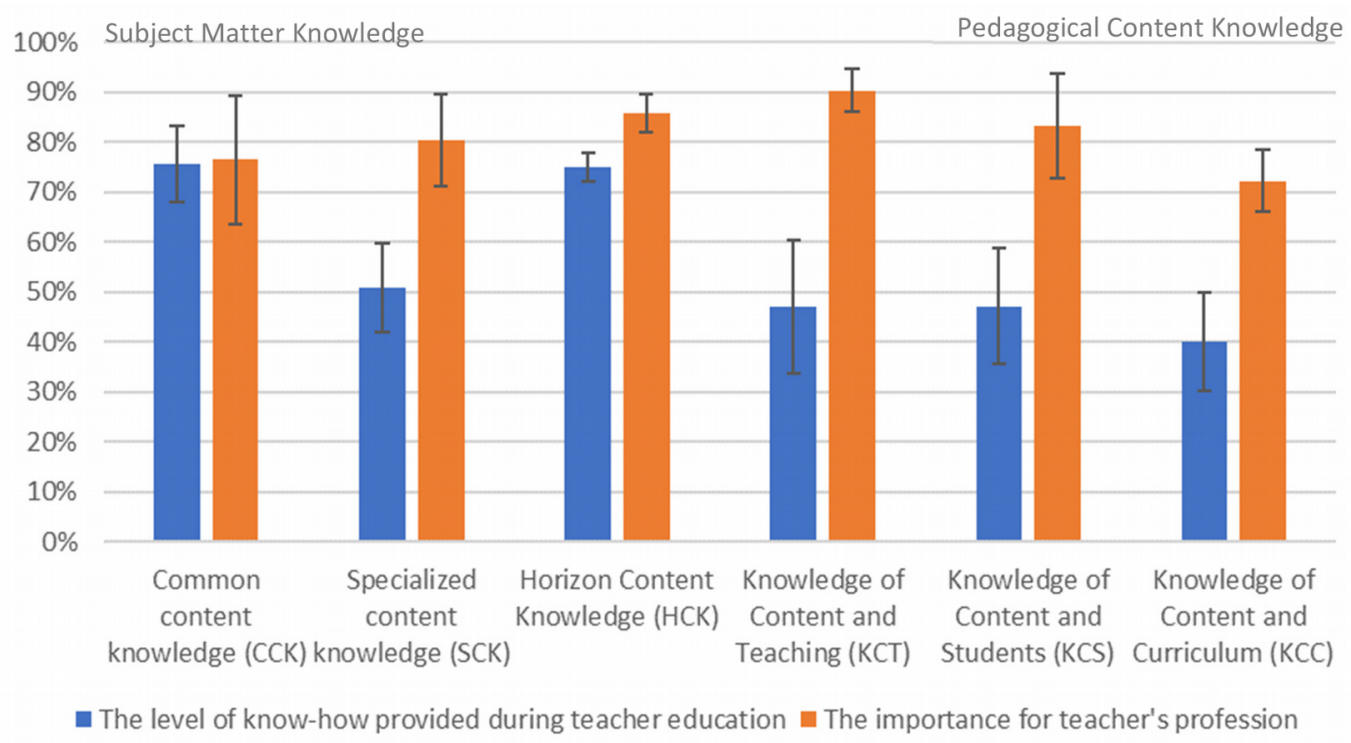

Figure 2. Mean values and standard deviations for graduated physics teachers' $(\mathrm{N}=26)$ views of the knowledge related to the domains of teacher knowledge provided during teacher education and of the importance of these domains for teacher's profession 
The Wilcoxon Signed Rank Test (Roster, Glynn \& Lee, 2006) indicated that teachers' considered importance of certain knowledge domains statistically significantly higher than the level of know-how they had been provided during teacher education (see Table 2). Specialized content knowledge (SCK) $Z=105, p<0.001$, Knowledge of content and teaching (KCT) $\mathrm{Z}=55, \mathrm{p}<0.005$, Knowledge of content and students (KCS) $\mathrm{Z}=118, \mathrm{p}<0.001$, and Knowledge of content and curriculum (KCC) $\mathrm{Z}=66, \mathrm{p}<0.005$ were such domains.

In the following sub-sections, these findings are opened furthermore for individual domains. Due to the big number of claims, only the most essential findings emerging from the tables presented are highlighted.

\begin{tabular}{|l|c|c|}
\hline & $\mathbf{Z}$ & $\mathbf{p}$ \\
\hline Common content knowledge (CCK) & 55 & 0.875 \\
\hline Specialized content knowledge (SCK) & 105 & $0.001^{* * *}$ \\
\hline Horizon Content Knowledge (HCK) & 15 & $0.043^{*}$ \\
\hline Knowledge of Content and Teaching (KCT) & 55 & $0.005^{* *}$ \\
\hline Knowledge of Content and Students (KCS) & 118 & $0.001^{* * *}$ \\
\hline Knowledge of Content and Curriculum (KCC) & 66 & $0.005^{* *}$ \\
\hline
\end{tabular}

$* p$-value $\leq 0.05, * * p$-value $\leq 0.01, p$-value $\leq 0.001$

Table 2. Results of the Wilcoxon Signed Rank Test

\subsection{Common Content Knowledge}

Figure 3 presents the claim-specific results related to the domain of Common content knowledge (CCK). The claims are presented under two themes for the sake of clarity, namely Areas of physics and General knowledge about physics as seen in the survey. The results show that teachers are satisfied how different areas of physics are addressed during their education in comparison to their importance for their profession, with some minor disparities. Regarding the claims related to general knowledge about physics, the results suggest that formal notations, measurement accuracy, and history of physics have had substantial emphasis in teacher education program in comparison to their significance for teaching profession.

The standard deviations reveal that data sets overlap to such a degree that this domain does not possess any significant disparities between teachers' evaluations of their needs and the education they have received.

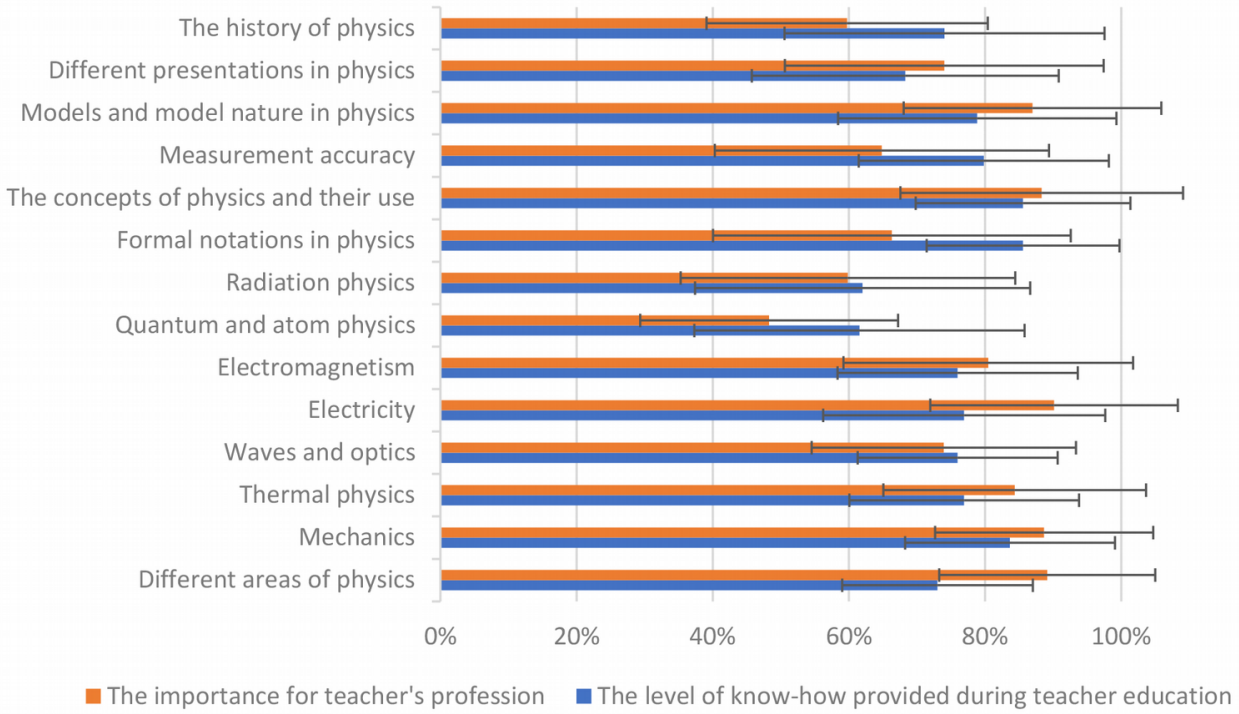

Figure 3. Mean values and standard deviations for graduated physics teachers' $(N=26)$ views of the knowledge related to the themes of Common content knowledge (CCK) provided during teacher education and of the importance of these domains for teacher's profession 


\subsection{Special Content Knowledge}

The results related to Special content knowledge are presented under four categories as seen in the survey in Figure 4. It should be noted that in this domain, teachers evaluated each claim visibly more important than addressed in their teacher education, the differences being up to 40 percentage points. These differences are witnessed in various topics, and especially the ones related to safety in experimental working cause concerns if teachers feel unqualified for safe experimental working at schools. The same trend is also seen under the claims related to planning teaching and evaluating learning. These findings are supported by the observation that there is no overlapping of the standard deviation bars in the claims.

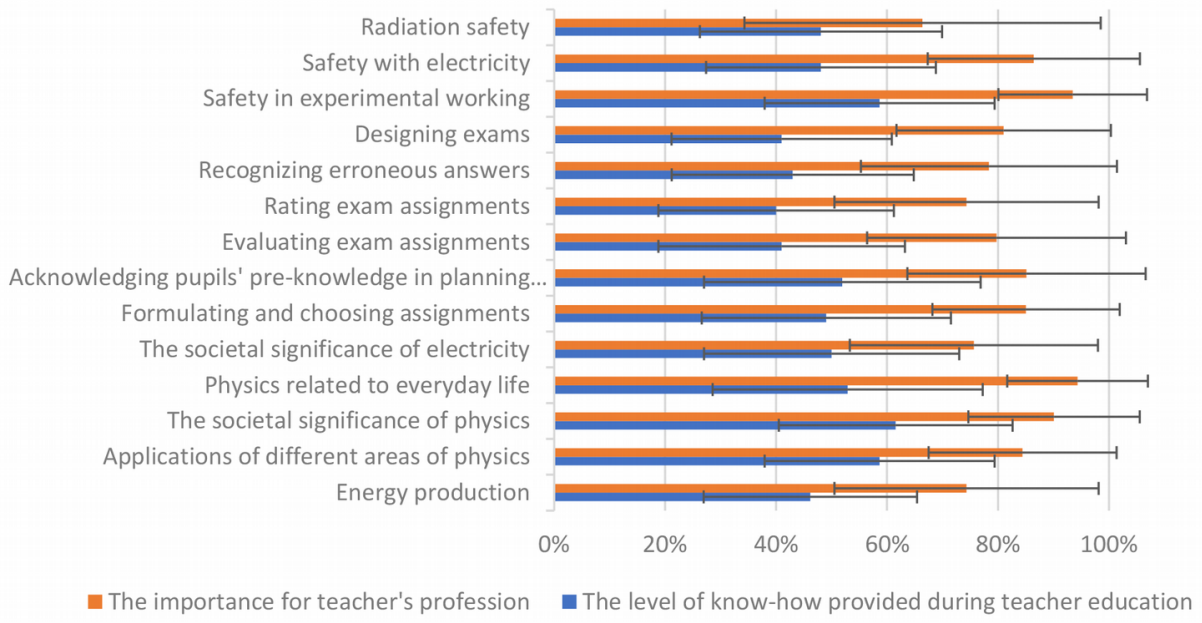

Figure 4. Mean values and standard deviations for graduated physics teachers' $(\mathrm{N}=26)$ views of the knowledge related to the themes of Special content knowledge (SCK) provided during teacher education and of the importance of these domains for teacher's profession

\subsection{Horizon Content Knowledge}

With respect to the claims related to Horizon content knowledge seen in Figure 5, both viewpoints evaluated by the teachers are well in agreement, the viewpoint of importance having slightly higher figures. As these claims are related to philosophical and structural nature of physics, this indicates that teachers seem to value this domain and how well it is addressed in their education. The standard deviation bars overlap in all claims greatly so that there does not appear to be significant differences between teachers' responses in these claims.

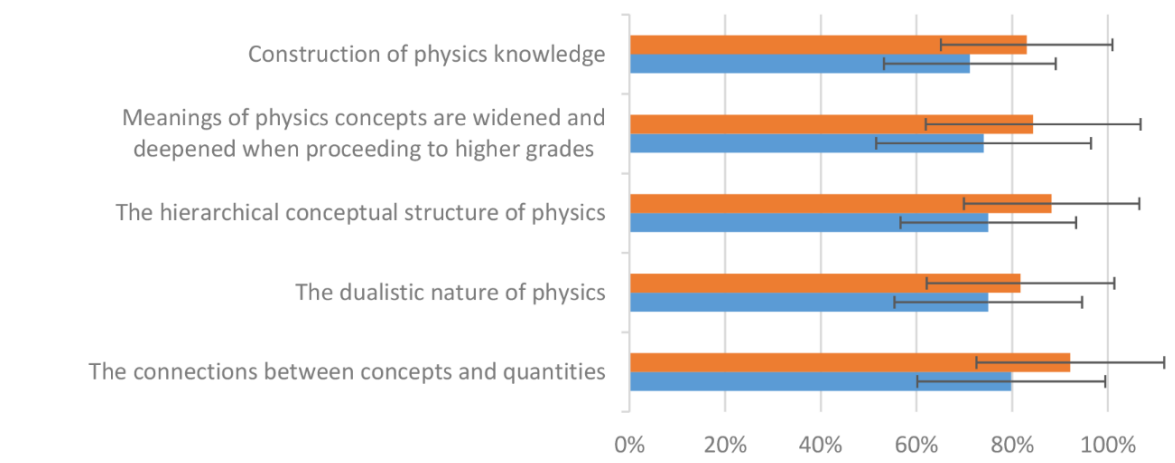

w The importance for teacher's profession

- The level of know-how provided during teacher education

Figure 5. Mean values and standard deviations for graduated physics teachers' $(N=26)$ views of the knowledge related to the themes of Horizon content knowledge ( $\mathrm{HCK}$ ) provided during teacher education and of the importance of these domains for teacher's profession 


\subsection{Knowledge of Content and Teaching}

When moving closer to pedagogical knowledge from pure physics, the disparity between teachers' evaluations for the know-how received during education and the importance of those characters became evident as the results related to the domain of Knowledge of content and teaching (KCT) in Figure 6 show. Each claim in this domain is evaluated higher than $80 \%$ when addressing the importance of those for teacher's profession whilst teachers' know-how received in their education has the mean value of $47 \%$. The disparity is rather large all over the claims but emphasized especially in setting learning aims, planning whole courses, controlling classroom, individualizing teaching, applying teaching methods, and supporting learning with evaluation as the standard deviation bars also indicate.

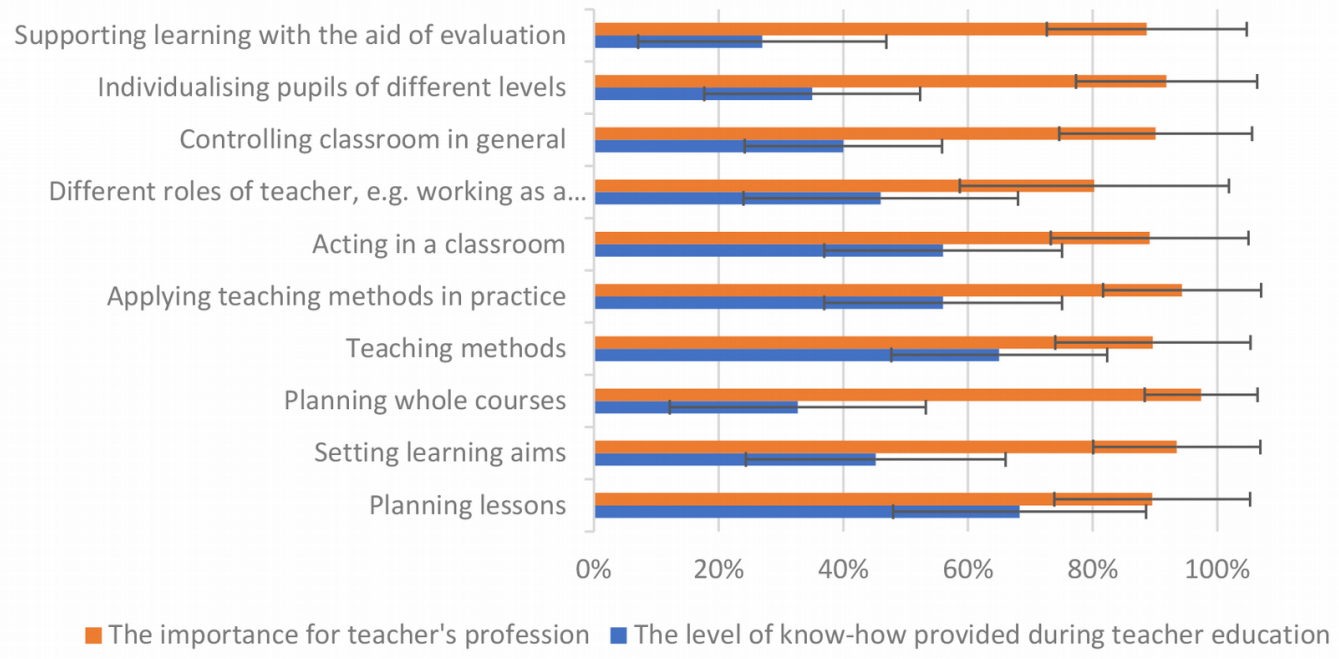

Figure 6. Mean values and standard deviations for graduated physics teachers' $(\mathrm{N}=26)$ views of the knowledge related to the themes of Knowledge of content and teaching (KCT) provided during teacher education and of the importance of these domains for teacher's profession

\subsection{Knowledge of Content and Students}

The findings related to the domain of Knowledge of content and students (KCS) seen in Figure 7 show that certain elements, such as pupils' misconceptions and learning theories have been addressed adequately in teacher education in comparison to their importance for teaching profession whilst some others have disparities up to 56 percentage points. The biggest disparities are seen in motivating pupils and evaluating learning. With respect the standard deviation bars, 10 claims out of 15 do not overlap which signals these differences to be significant.

\subsection{Knowledge of Content and Curriculum}

The results concerning the last domain Knowledge of content and curriculum (KCC) are presented in Figure 8. Again, it is seen that based on teachers' evaluations, their education has not answered their professional needs. The disparity was evident in all claims but emphasized especially with the themes of using educational materials in teaching and local school curricula. As the standard deviations are rather large in this domain, these bars overlap in all but two claims (local curricula of schools and using educational materials in teaching). These findings suggest that these domains possess the greatest differences between the teachers as clearly there are certain teachers who do not experience much of disparity even if the percent values differ greatly. 


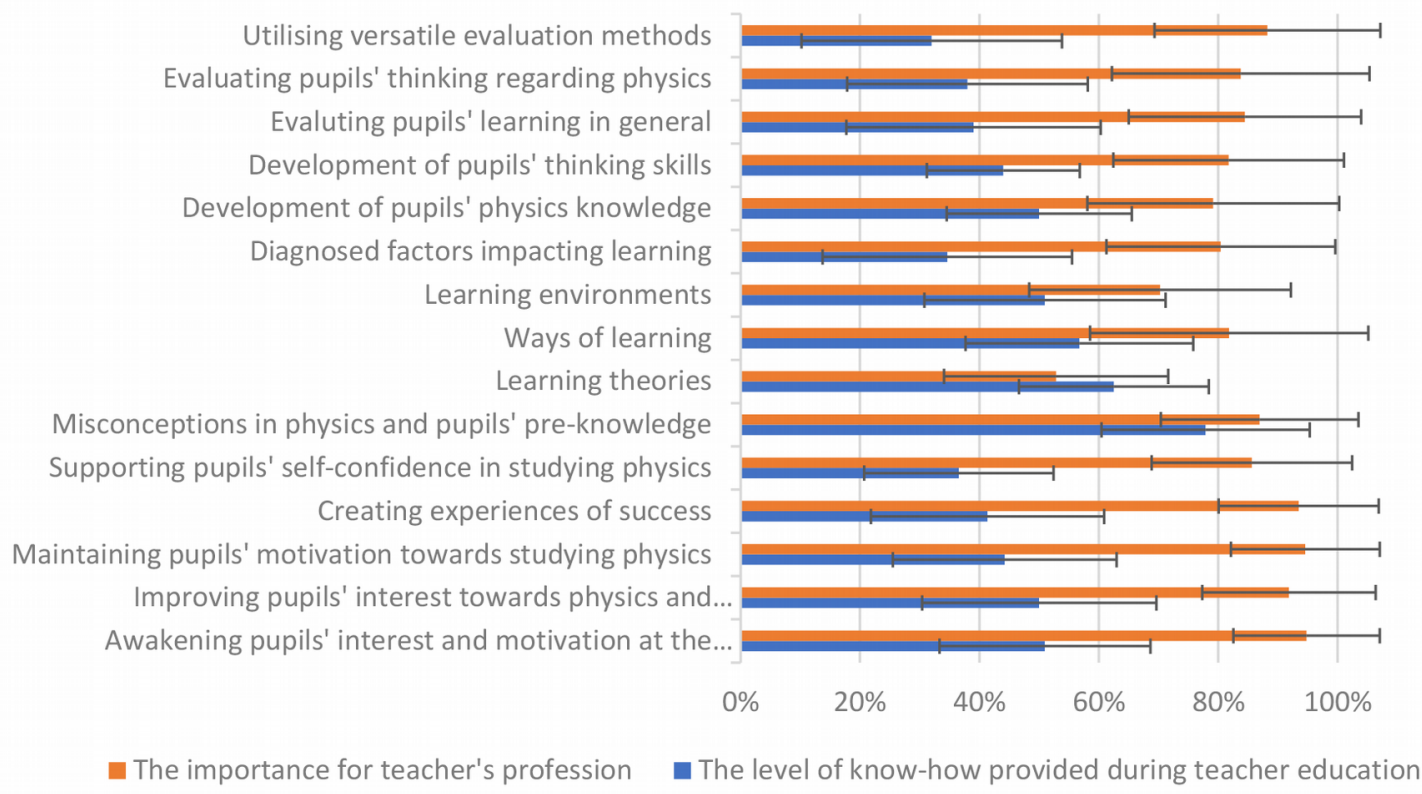

Figure 7. Mean values and standard deviations for graduated physics teachers' $(\mathrm{N}=26)$ views of the knowledge related to the themes of Knowledge of content and students (KCS) provided during teacher education and of the importance of these domains for teacher's profession

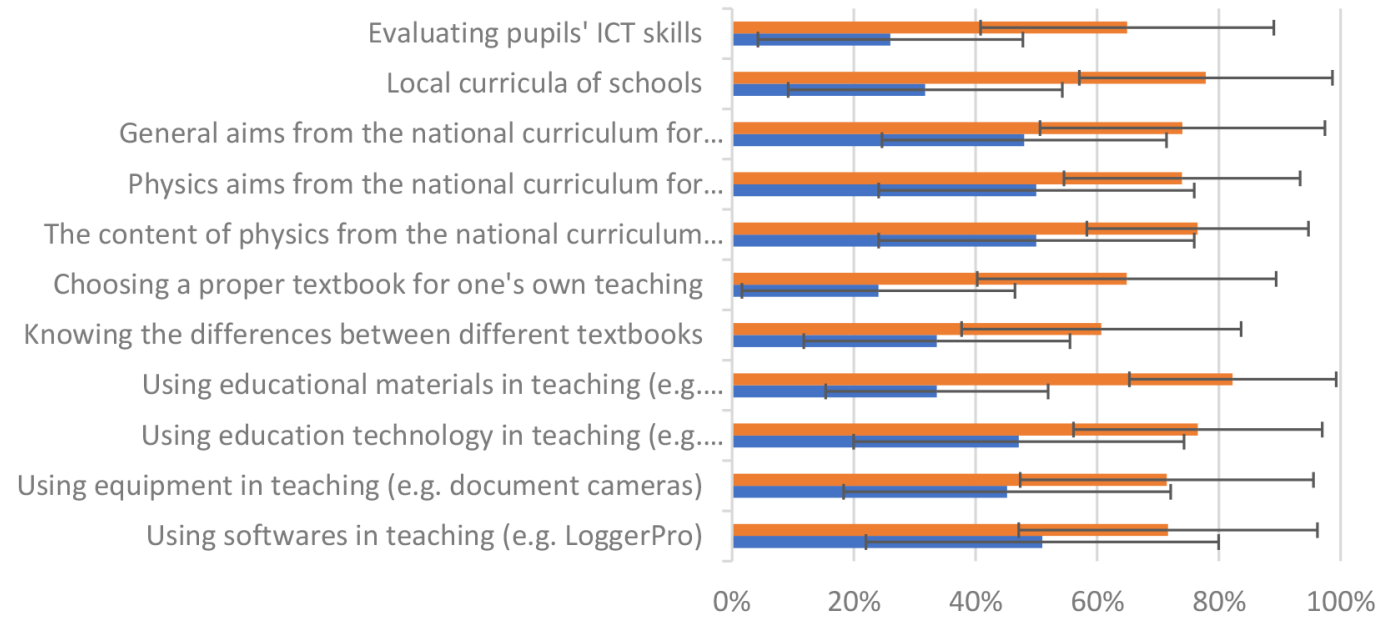

- The importance for teacher's profession

The level of know-how provided during teacher education

Figure 8. Mean values for graduated physics teachers' $(\mathrm{N}=26$ ) views of the knowledge related to the themes of Knowledge of content and curriculum (KCC) provided during teacher education and of the importance of these domains for teacher's profession

\section{Discussion and Conclusions}

In the course of this article, physics teachers' views about their teacher education program and their professional needs have been evaluated. With respect to the first research question "How do graduated physics teachers evaluate their teacher education program in terms of different domains of teacher knowledge?" it was revealed that teachers see that the domains related to common content knowledge and structures of physics have been addressed adequately in their teacher education. Then again, the domains related to teaching, learning, evaluating, grading, and motivating pupils received significantly less favorable evaluations from the teachers. This suggests that the greatest deficiencies in this physics teacher 
education program lie on pedagogical content knowledge with its various sub-domains. This finding is well in agreement with the findings from mathematics teacher education program evaluation study (Koponen et al., 2016, 2017).

Regarding the second research question "How do graduated physics teachers evaluate the importance of different domains of teacher knowledge for their profession?" it was shown that teachers evaluate the importance of every domain of teacher knowledge highly, with mean values varying from $72 \%$ to $90 \%$. Within all the domains, only a few claims, such as content related to quantum and atomic physics and learning theories, received significantly low percentages but most themes seen in the claims were seen important for teachers' profession, the emphasis being on the domain Knowledge of content and teaching. Thus, the claims presented seem to be relevant for teacher profession.

Our results show that according to teachers there is a disparity of teachers' needs and what is delivered in their teacher education. This indicates that the physics teacher education program needs critical evaluation for assuring that the most essential domains of teacher knowledge with their sub-structures are addressed adequately during teacher education. It should be remembered that even if teachers state that certain domains have not been addressed in their education adequately, it might also mean that they misremember or misinterpret that. However, clearly these teachers have experienced that their education has not been ready to answer their needs, and this message should be taken seriously amongst teacher educators.

Whilst comparing our results to the previous study from Finland (Asikainen \& Hirvonen, 2010), it is seen that the findings emerging from the studies conducted share similar features between more experienced and more novice teachers, but the spectrum is not as wide amongst more experiences teachers. With respect to a research conducted in New Zealand, there are evident differences between the studies as in New Zealand pedagogical knowledge seems to have a significantly greater emphasis in comparison to Finland (Buabeng et al., 2016). Regarding the studies related to certain domains of teacher knowledge (e.g. Abd-El-Khalick \& BouJaoude, 1997), one should be cautious in comparisons as certain sub-themes might get a different emphasis whilst the evaluation has a tighter focus.

The examples from different countries with significantly different results introduced here indicate that teachers' views can differ depending on the educational culture. For example, in New Zealand subject matter knowledge is not emphasized in their teacher education (Buabeng et al., 2016) when in Finland it has a great emphasis. This suggests that these types of studies should not be bound only to certain theoretical framework but also to country's education system.

When it comes to trustworthiness of this study, a few things should be mentioned. First, the survey instrument was developed based on research literature by researchers with familiarity with physics, physics teaching, physics teacher education, and MKT model, and according to our findings it serves its purpose well. However, we do realize that it could use some rephrasing and possible different emphases for the sake of unambiguousness. We strongly encourage other researchers to develop the survey furthermore. Second, certain claims might have characteristics from more than one domain of teacher knowledge which raises an issue about their exclusiveness. As there is not one solution for this issue, we decided that each claim should belong to one domain only according to its major characteristics. This categorization has been checked by various researchers, and the final categorization was satisfactory for all of them. To give readers a chance to evaluate this, results are written openly that the sub-structures of all domains are shown in them. It should also be remembered that the figures concerning the two viewpoints evaluated should not be treated as directly comparable as different scales were used in the survey, and interpretations from statistical figures calculated from ordinal data should be drawn with caution. One more thing to remember is that our sample might not represent the whole cohort of graduated teachers, because answering the survey was voluntary, and we reached $57 \%$ of them. This might cause some bias, because likely the teachers who returned the survey have higher motivation than average teachers which might be reflected in the results. 
Our results suggest that our PKT framework offers a functional base for evaluating physics teacher knowledge. Naturally, the different philosophical nature of mathematics and physics is seen within the domains but the underlying idea of dividing teacher knowledge in six domains functions well. We think that this type of structure would work with most natural sciences, and we encourage other science education researchers to apply this model to describe teacher knowledge in their areas. As Ball et al. (2008) did not claim his framework to be perfect, we also acknowledge possible needs for development, but this model definitely offers a good starting point. Teachers' needs change with society, and this means that teacher knowledge models should be treated as dynamic systems that are not isolated from their surroundings but reflect possible changes in society and schools, such as reforms in national curricula (Finnish National Board of Education - FNBE, 2014). As a matter of fact, we should keep it in mind that certain elements in the domains, such as content knowledge and misconceptions, remain relatively unchanged over time whilst some others reflect the changes in society more rapidly.

Our findings motivate us teacher educators to evaluate the content and emphases in the entity of physics teacher education program. However, there are certain national guidelines for teacher degrees that set limits for modifying these programs. For example, it is not possible to add new courses or widen the current ones without removing something that already exists. This raises an important question: what sort of emphases should different teacher domains have from the viewpoint of teacher education? In its current form the domains related to content knowledge are emphasized but we should think about if we are ready to change this somehow for the sake of better knowledge related to content and teaching. It has been suggested that there is a certain "optimal" amount of university studies that bring significant benefit for learning (Monk, 1994). This finding makes us to ponder that could we get the same satisfaction and learning for content knowledge also with less courses which would liberate time for topics related to other domains. These give an idea for a new research project where similar survey is given for more experienced teachers because they might offer new interesting insight for teachers' needs.

We suggest that pre-service teachers should be explicitly introduced a framework for teacher knowledge in their education. This would serve them by means of showing that there is a theoretical foundation for teacher knowledge which could help them to evaluate their own learning furthermore. Optimally, the whole entity of physics teacher education should be constructed so that the target domain of each course would be made evident for students. This would also serve teacher educators as it would necessarily reveal if there are evident deficiencies concerning the most important elements of teacher knowledge.

\section{Declaration of Conflicting Interests}

The authors declared no potential conflicts of interest with respect to the research, authorship, and/or publication of this article.

\section{Funding}

The authors received no financial support for the research, authorship, and/or publication of this article.

\section{References}

Abd-El-Khalick, F., \& Boujaoude, S. (1997). An exploratory study of the knowledge base for science teaching. Journal of Research in Science Teaching, 34(7), 673-699. https://doi.org/10.1002/(SICI)10982736(199709)34:7<673::AID-TEA2>3.0.CO;2-J

Asikainen, M.A., \& Hirvonen, P.E. (2010). Finnish Cooperating Physics Teachers' Conceptions of Physics Teachers' Teacher Knowledge. Journal of Science Teacher Education, 21, 431-450. https://doi.org/10.1007/s10972-010-9187-y

Ball, D.L., Thames, M.H., \& Phelps, G. (2008). Content Knowledge for Teaching - What makes it special? Journal of Teacher Education, 59(5), 289-407. https://doi.org/10.1177/0022487108324554 
Buabeng, I., Conner, L., \& Winter, D. (2016). Physics teachers' views on their initial teacher education. Australian Journal of Teacher education, 41(7), 36-55. https://doi.org/10.14221/ajte.2016v41n7.3

Dirac, P.A.M. (1940). The relation between mathematics and physics. Published in Proceedings of the Royal Society (Edinburgh), Vol.59, 1038-1039, Part II, 112-129. https://doi.org/10.1017/S0370164600012207

Finnish National Board of Education - FNBE (2014). National Core Curriculum for Basic Education 2014. Helsinki: Next Print Oy.

Halloun, I.A. (2004). Modeling Theory in Science Education. Dordrecht: Kluwer Academic Publishers.

Hecht, E. (2002). Optics. San Francisco: Pearson.

Hestenes, D., Wells, M., \& Swackhamer, G. (1992). Force concept inventory. The Physics Teacher, 30, 141-158. https://doi.org/10.1119/1.2343497

Hill, H.C., Ball, D.L., \& Schilling, S.G. (2008). Unpacking pedagogical content knowledge: Conceptualizing and measuring teachers' topic-specific knowledge of students. Journal of Research in Mathematics Education, 39(4), 372-400.

Keller, M.K., Neumann, K., Fischer, H.E. (2017). The impact of physics teachers' pedagogical content knowledge and motivation on students' achievement and interest. Journal of Research in Science Teaching, 54(5), 586-614. https://doi.org/10.1002/tea.21378

Knight, R.D. (2014). Physics for scientists and engineers - A strategic approach (3th edition). San Francisco: Pearson.

Koponen, M., Asikainen, M.A., Viholainen, A., \& Hirvonen, P.E. (2016). Teachers and their educators Views on content and development needs in mathematics teacher education. The Mathematics Enthusiast, 13(1), 148-170.

Koponen, M., Asikainen, M.A., Viholainen, A., \& Hirvonen, P.E. (2017). How education affects mathematics teachers' knowledge: Unpacking selected aspects of teacher knowledge. Eurasia Journal of Mathematics, Science \& Technology Education, 13(6), 1943-1980. https://doi.org/10.12973/eurasia.2017.01209a

Kurki-Suonio, K., \& Kurki-Suonio R. (1994). Fysiikan merkitykset ja rakenteet (The Meanings and Structures of Physics). Helsinki: Limes ry.

McDermott, L. (1990). A perspective on teacher preparation in physics and other sciences: The need for special science courses for teachers. American Journal of Physics, 58(88), 734-742.

https://doi.org/10.1119/1.16395

Monk, D.H. (1994). Subject area preparation of secondary mathematics and science teachers and student achievement. Economics of Education Review, 13(2), 125-145. https://doi.org/10.1016/0272-7757(94)90003-5

Nivalainen, V., Asikainen, M.A., \& Hirvonen, P.E. (2013). Preservice teachers' objectives and their experience of practical work. Physical Review Special Topics - Physics Education Research, 9(1), 010102. https://doi.org/10.1103/PhysRevSTPER.9.010102

OECD. (2018). http://www.oecd.org/pisa/

OECD. (2015). http://gpseducation.oecd.org/CountryProfile?primaryCountry=FIN\&treshold=10\&topic=PI

Rosner, B., Glynn, R.J., \& Lee, M.L.T. (2006). The Wilcoxon signed rank test for paired comparisons of clustered data. Biometrics, 62(1), 185-192. https://doi.org/10.1111/j.1541-0420.2005.00389.x

Schroeder, D.V. (2000). An introduction to thermal physics. San Francisco: Addison Wesley. 
Shulman, L.S. (1986). Those who understand: Knowledge growth in teaching. Educational Researcher, 15(2), 4-14. https://doi.org/10.3102/0013189X015002004

Shulman, L.S. (1987). Knowledge and teaching: Foundations of the new reform. Harvard Educational Review, 57, 1-22. https://doi.org/10.17763/haer.57.1.j463w79r56455411

TIMMS \& PIRLS (2015). http://timss2015.org/

van Driel, J.H., Verloop, N., \& de Vos W. (1998). Developing science teachers' pedagogical content knowledge. Journal of Research in Science Teaching, 35(6), 673-695. https://doi.org/10.1002/(SICI)10982736(199808)35:6<673::AID-TEA5>3.0.CO;2-J

\author{
Published by OmniaScience (www.omniascience.com) \\ Journal of Technology and Science Education, 2020 (www.jotse.org)
}

\title{
(c) $($ (i) $(9)$
}

Article's contents are provided on an Attribution-Non Commercial 4.0 Creative commons International License. Readers are allowed to copy, distribute and communicate article's contents, provided the author's and JOTSE journal's names are included. It must not be used for commercial purposes. To see the complete licence contents, please visit https://creativecommons.org/licenses/by-nc/4.0/. 